\title{
In Search of Fundamentals of Thai Architectural Identity: A Reflection of Contemporary Transformation
}

\author{
By Vimolsiddhi Horayangkura*
}

\begin{abstract}
The long historical development of Thai Architecture has revealed inherent fundamentals of architectural identity that reflect enduring Thai wisdom. Upon closer scrutiny of contemporary architecture, fundamental Thai characteristics persist in the present-day context, and unveil the inherent approach to Thai architectural identity development. The objectives of this research focus on: 1) reviewing theories, concepts and guidelines in the development of modern Thai architectural identity; 2) making architectural surveys in various regions of Thailand, especially prominent works relevant to modern Thai identity transformation; 3) identifying the concepts, inspirations and directives of creation held by architects and academics. Twenty specified architects and academics were interviewed and the outputs were analyzed through content analyses based on the research conceptual framework. Through integrated analyses of these studies, five major categories of fundamentals were revealed. The abstract qualities reflect the enduring Thai spirit nurtured through conditions of tropical climate and Thai wisdom. The non-abstract characteristics are mainly the outcomes of localism for both traditional and contemporary architecture such as the use of local materials and the applications of formal pattern. Among the various dimensions of aesthetics, the two dominant characteristics are the use of curvilinear lines, such as the graceful catenary curve, and refined ornamentation. Symbolism through the application of iconic images is apparent in both traditional and contemporary architecture in design elements such as the high-pitched gable roof and lotus-shaped motifs. Symbolism derives from the prevalent belief system in reincarnation and the cosmological model. Thainess encompasses the spirit-driven formal and popular development, and the joyful nature of the Thais regarding the formal multiplicity and colorful manifestation. More research should be focused on the meaningful symbolic intervention rather than the iconic applications of conventional images and elements. Finally, the confirmed fundamentals would be the basis for creating a distinctive Thai architectural identity in the more globalized future.
\end{abstract}

\section{Introduction}

Western influences had critically transformed the urban landscape over the land known as 'Siam' since the period of the reigns of King Rama IV and V. Under the approach of creating 'civilization (Siwilai),' buildings of European architectural style were constructed to accommodate the functions of

\footnotetext{
* Professor, Thammasat University (APTU), Thailand.
} 
modernized society. ${ }^{1}$ Such underlying political bias in the period of colonialism had further been utilized in later eras when democracy and national economic development plans were introduced. Formal education based on western discipline has since then significantly and enduringly set up the foundation for modern design. ${ }^{2}$ At a geographic and cultural crossroads, under the influx of globalization, architecture in Thailand in general inevitably turns to an international outlook.

The long historical development of Thai architecture does, however, reveal the fundamentals of Thai architectural identity that reflect enduring Thai wisdom. Further investigation of these fundamentals in the present-day contexts of the more innovative approaches would unveil more distinctive or even avantgarde Thai characteristics reflected in buildings of national significance such as the National Assembly, the National Conference Center and the Thai Pavilion at World Expo. ${ }^{3}$

\section{Research Objectives}

In search for architecture that embodies the nation's identity, this research focuses on the development of modern Thai architectural identity (MTAI) based on the critical investigation of design fundamentals. ${ }^{4}$ The research objectives are as follows:

1. Reviewing theories, concepts and design guidelines of modern Thai architectural identity; developing research conceptual framework comprised of key/related concepts and influencing factors.

2. Making architectural surveys in various regions of Thailand, both documentary and empirical, including case studies and prominent works which are in accordance with the relevant concepts of modern Thai identity transformation.

3. Identifying the concepts and inspirations held by architects and academics, as well as influences and directives of creation in association with the fundamentals of modern Thai identity.

4. Through the integrated analyses of the above studies, fundamentals of Thai identity in contemporary architecture would be proposed.

1. Pirasri Povatong, Building Siwilai: Transformation of Architecture and Architectural Practice in Siam During the Reign of Rama V, 1868-1910 (Doctoral Dissertation, University of Michigan, 2011), 5-10.

2. Vimolsiddhi Horayangkura, The Architecture of Thailand: Change amid Continuity, in Transforming Tradition: Architecture in the ASEAN Countries, ed. Jon Lim (Singapore: Unique Press, 2001), 240-245.

3. Vimolsiddhi Horayangkura, "The Creation of Cultural Heritage: Towards Creating a Modern Thai Architectural Identity,” Manusya Journal of Humanities 13, no. 1 (2010): 60-80.

4. Vimolsiddhi Horayangkura, Bootsakorn Settaworakit, and Vira Inpuntung, Fundamentals of Thai Architectural Identity. A research report of the research series project: The Creation of Modern Thai Architectural Identity, funded by The Thailand Research Fund. (Pathumthani: Faculty of Architecture and Planning, Thammasat University, 2015). 


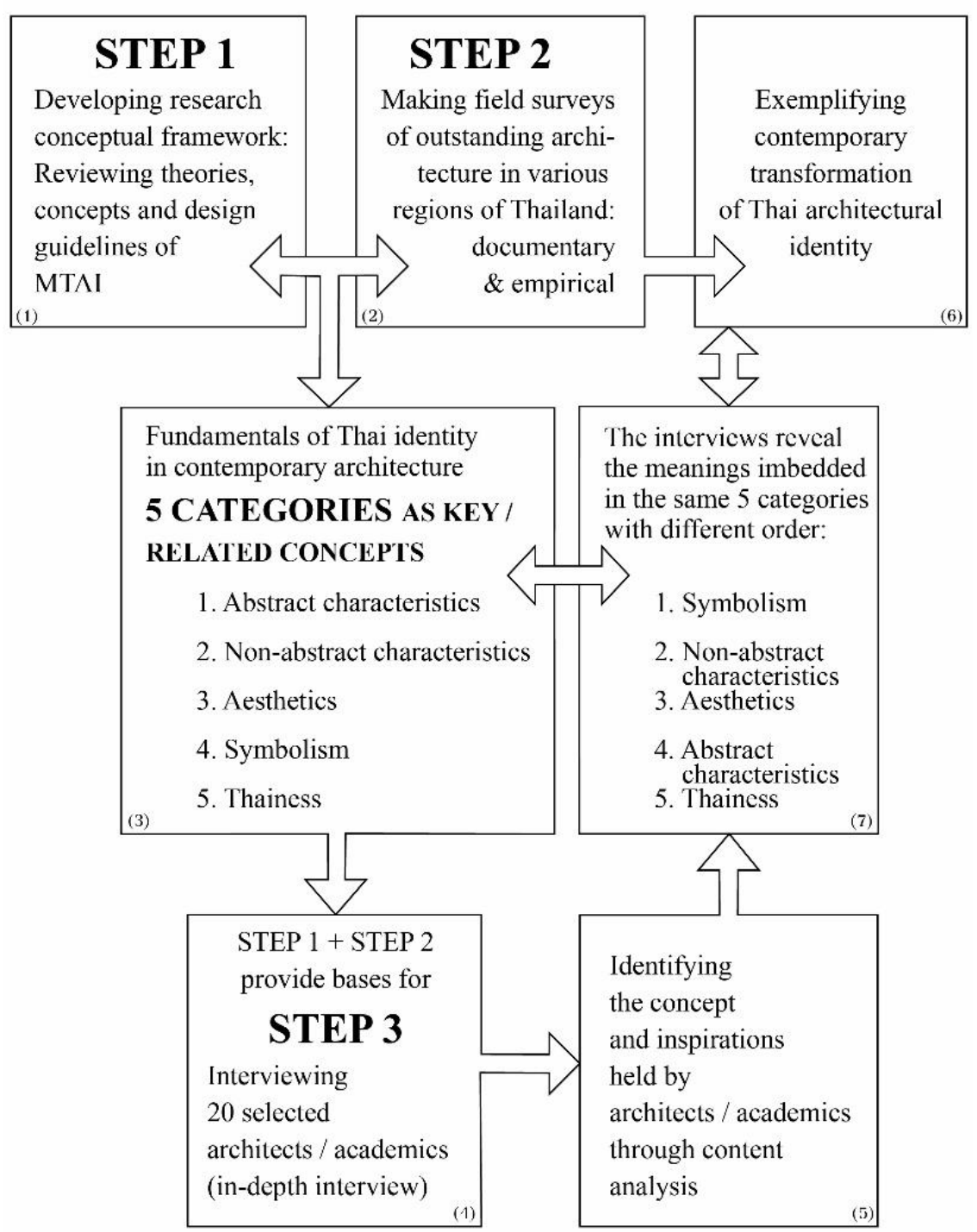

Figure 1. Steps in the Research Process with Methods and Expected Outputs from (1) to (7)

\section{Research Methodology}

The following specific methods were undertaken along the inductive approach (Figure 1):

Step 1: In developing the research conceptual framework, various theories and concepts were employed regarding fundamental characteristics. Through documentary research, the key concepts together with related concepts and influencing factors were identified. Relevant research works and prominent writings, together with case studies portraying the cultural transformation of architectural design in contemporary context were the primary sources of analysis.

Step 2: Emphases were given to the field surveys of outstanding 
architecture, particularly those that were awarded or widely publicized by professional associations for exhibiting Thai characteristics transformed for the modern society. Special attention was given to highly criticized cases of which the architects demonstrated self-conscious expression of Thainess in the modern context. The surveys, which included visual documentation, were undertaken regionally according to the conceptual framework.

Step 3: The fundamentals gathered through step 1 and step 2 were the bases for interviewing twenty selected architects and academics (see note 20) in terms of relevant design approaches and inspirations. Content analyses of all interview inputs were conducted based mainly on the major categories of fundamentals formulated earlier in step 1 and step 2.

\section{Results and Discussion: Analyses of Reviews and Surveys}

Through integrated analyses of works in step 1 (reviews) and step 2 (surveys), five categories of fundamentals as key/related concepts of Thai architectural identity in contemporary context can be identified.

\section{Abstract Characteristics}

Abstract characteristics are fundamental in Thai architectural identity from past to present. They are enduring phenomena which are widely accepted in Thai society. They can be considered the 'core dimension' of Thai architecture, representing the intangible aspect of built environment. Abstract characteristics include multiple aspects such as:

Lightness/buoyancy is a rather common characteristic in architecture, ${ }^{5}$ found in a structure consisting of a roof mass with extended eaves and supported by individual columns in the pattern of colonnade or raising the building above ground. Another approach to create perceptual opportunity of lightness/ buoyancy is to locate the building over water. ${ }^{6}$ Sumet Jumsai, A prominent architect, emphasizes the relationship between buildings and water as an architectural setting for expressing the Thai identity. These formal patterns recur in architectural development from past to present.

The upward curves of the roof and base seen in past temples as put forward and illustrated by Joti Kalyanamitra ${ }^{7}$ have been transformed into straight ones as can be seen in the current ubosot of Wat Phra Dhammakaya (Figure 2).

\footnotetext{
5. Nij Hinchiranan, "Thai Architecture: Indigenous Architecture for People of the Central Region," ASA Journal of the Association of Siamese Architects (1996): 110-117.

6. Sumet Jumsai, "Water: Origins of Thai Culture," in Thai Charac-teristics, ed. M.R. Kukrit Pramoj (Bangkok: Thai Wattana Panich, 1982), 164-187.

7. Joti Kalyanamitra, "Traditional Thai Architecture," in Thai Charac-teristics, ed. M.R. Kukrit Pramoj (Bangkok: Thai Wattana Panich, 1982), 310-364.
} 


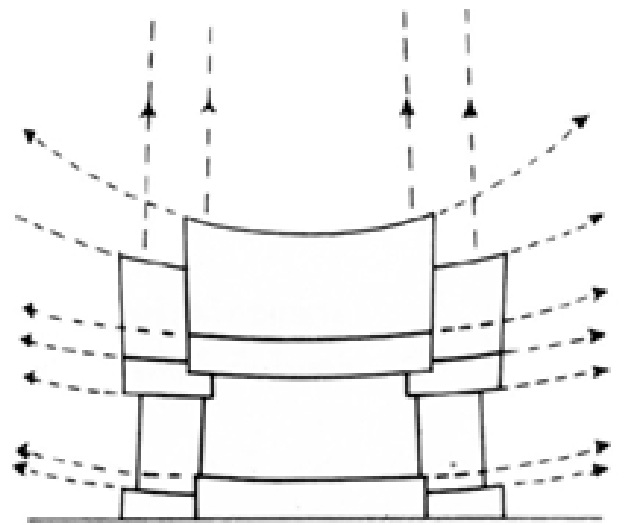

(A)

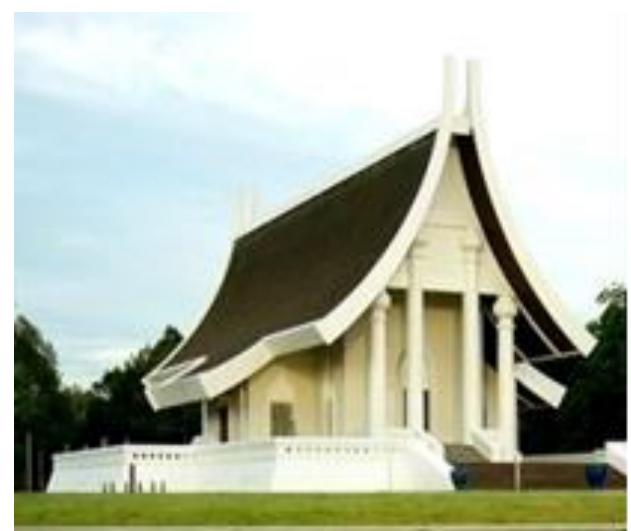

(B)

Figure 2. (A) Upward Curves of Roof and Base of Past Temples; (B) Contemporary Ubosot of Wat Phra Dhammakaya

Source: (A) Joti Kalyanamitra, Traditional Thai Architecture. Thai Characteristics (in Thai) (Bangkok: Thai Wattana Panich, 1982), 345.

The reciprocal characteristics of transparency and spaciousness are the outcome of architectural solutions that are responsive to the need of a comfortable living environment in hot and humid climates. There are repeated features that generate transparency such as the application of colonnade along a corridor, a roof structure with a skylight or covered with transparent material, the use of lattice/louver in general or specific pattern, etc.

Spaciousness is inherent in indoor space of traditional living units which are apparently empty spaces (without furniture or partitioning). A courtyard surrounded by built units or the familiar elevated central terrace known as "chaan" normally conceived in traditional Thai houses is intrinsically spacious. It is open and airy for tropical living. Chaan loosely connects the multi-unit house compound. The semi-outdoor attached veranda, serving the social function of family, is the in-between space protected from the heat of tropical climate. The 'chaan' and the 'attached veranda,' each becomes an inbetween element that reflects the Yin-Yang duality concept of eastern thinking.

Enclosure is an abstract quality inherent in courtyard structures of enclosed conventional religious complexes as well as in modern facilities, each with a corridor and colonnade surrounding the central open space (Figure 3). The enclosed spaces generate a sense of safety and relaxation, as well as privacy. They dominate the spatial arrangement in various regions of the world and vary according to local socio-cultural factors. ${ }^{8}$ Some modern hotels in Chiang Mai (Figure 3B) have been laid out with Chinese-influenced courtyards and featuring a local temple-enclosed space.

8. Amos Rapoport, House Form and Culture (Englewood Cliffs, N.J.: Prentice Hall, 1969), 46-82; Yi-Fu Tuan, Space and Place: The Perspective of Experience (Minneapolis: University of Minnesota Press, 1981), 101-117. 


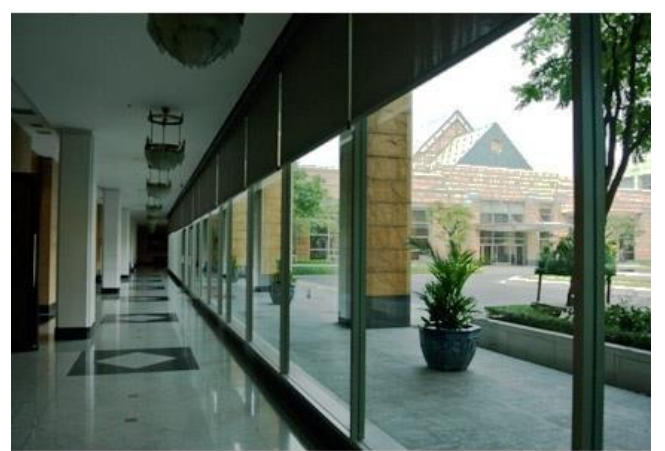

(A)

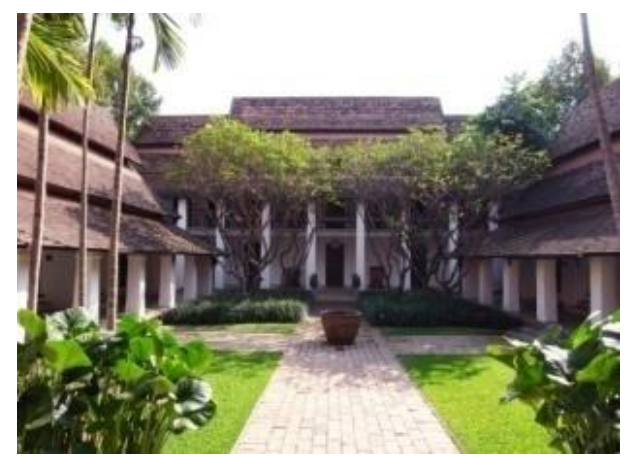

(B)

Figure 3. (A) Inside Corridor and Colonnade at the Headquarters of Thailand's Ministry of Foreign Affairs; (B) Courtyard and Colonnade at Rachamankha Hotel in Chiang Mai

One of the approaches in creating a Thai identity in modern architecture is to maintain shadiness which would result in the feeling of coolness. This is the "Rom Ruen Quality" in association with "The Tree" - one of the essential patterns that characterize the traditional house. ${ }^{9}$ Through the natural process, shadiness and coolness can be attained from bushes or foliage. Sources of water and air movement through a good ventilation system contribute additional coolness. These fundamentals of Thai architectural characteristics are essential to the current environmental context in which the problems of global warming have to be addressed through the application of green architecture and sustainable development.

The brightness/dimness/darkness sequence of abstract qualities is inherited from Thai wisdom to create visual comfort through transitional adaptation from a rather dark space of living unit to the bright area of an open elevated terrace via the attached verandah which is comparatively dim. The projected eaves and the shady trees have substantially reduced the intense brightness of the central open space. Nij Hinchiranan revealed the Thai wisdom regarding the sequence of darkness, dimness and brightness following the setting of tradition Thai house in the order of the cabin, the veranda and the open elevated terrace that are responsive to the varying needs of natural lighting. ${ }^{10}$ It should be noted that contemporary designs have provided a semi-outdoor space known as the 'grey area' which has efficiently utilized natural light while glare is minimized.

Traditional Thai houses are mostly settled amid tranquil and quiet atmospheres, which are much needed for present-day residential communities in bustling cities. Natural environments surrounding the external settings and the internal court with dense foliage create tranquil and quiet milieus which are fundamental Thai characteristics. The temple compounds surrounded by cloisters are ideal settings of tranquility. As Vannapa Pimviriyakul has noted in her observation of ubosoth of Wat Yai: "The most profound and important element of experiential quality of the ubosoth of Wat Yai is the atmosphere of

9. M.L. Piyalada Thaveeprungsriporn, "Ruan Thai: An Aesthetic of Feminity," in Architecture Wisdom, ed. Ornsiri Panin et al. (Bangkok: Archipress, 2003), 68-96.

10. For reference, see note 5. 
kwaam sa-ngop that enables Buddhists to attain a peaceful mind. This quality reflects the Buddhist view that kwaam sa-ngop of a place brings peaceful resolution to the mind of the worshipper. This, in turn, allows one to reflect on the teachings of Buddha. Similar to other Thai ubosoth, the physical character of the ubosoth of Wat Yai contributes to a quiet, cool, and restful atmosphere which allows one to become calm, and to attain the emotion of being protected and sheltered, and at peace mentally and spiritually." 11

\section{Non-Abstract Characteristics}

Non-abstract characteristics are highly regarded as instrumentalized outcomes of localism. In connection with locality and necessary transformations, both traditional and contemporary architecture achieve similar characteristics. The following non-abstract characteristics can be identified:

Traditional architecture is essentially in harmony with nature regarding climatic condition and the use of local materials and builders. Vernacular architecture is imbedded in nature and transformed into contemporary vernacular under the impact of regionalism. ${ }^{12}$ One of the approaches of creating a Thai identity in modern architecture is to design in harmony with nature and being an integral part of the natural setting - amid trees and water. The integration with a dense growth of trees helps reduce the intense heat of the tropical region. The Thai wisdom used in creating comfortable living conditions is thus indigenously preserved in the modern context.

However, the past architecture that supported water-dependent daily life has been transformed into a mere symbolic application of water to be relevant to a present-day land-based society.

The traditional green areas on elevated terraces were transformed into courtyards and surrounding areas. To fully utilize the ground level area, more attention is paid to layout planning to gain more green areas and natural environments. In an enclosed space, additional green space can be used to include the vertical garden. The open spaces of development projects are predetermined by legal controls for FAR (floor area ratio), OSR (open space ratio) and BCR (building coverage ratio). Moreover, LEED (Leadership in Energy and Environmental Design) and TREES (Thai's Rating of Energy and Environmental Sustainability) are widely accepted as standards to conserve energy as well as create environmental sustainability.

In considering the various aspects of Thai wisdom as codified in the traditional Thai houses (Ruen Thai) of the Central Region ${ }^{13}$ together with the contemporary social and environmental context regarding familiarity of physical pattern, current technology and the vernacular design, certain transformations of architectural features that reflect Thai wisdom can be identified. They are: 1)

11. Vannapa Pimviriyakul, Light in Thai Places: A Cultural Interpretation of Thai Buddhist Architecture (College Station: Texas A\&M University, 2001), 181.

12. William Siew Wei Lim and Tan Hock Beng, The New Asian Architecture (Singapore: Select Books, 1998).

13. Ruethai Chaichongrak et al., The Thai House: History and Evolution (Bangkok: River Books, 2002), 19-97. 
climatic protection in the direction of tropical architecture with traditional essence; 2) semi-outdoor space or 'grey area' in modified climatic condition for outdoor living; 3) enclosed courtyard with refined scale and proportion, visual comfort and aesthetic attraction. All these contemporary transformations unveil the wisdom and fundamental characteristics, and according to Rapoport, ${ }^{14}$ the multiple influencing factors that shape the built environment.

One of the non-abstract qualities is the local characteristics of contemporary architecture. This uniqueness indicates cultural inheritance through in situ practices over time, such as the uses of local materials and the applications of formal pattern, components and elements. However, prominent features of remote vernacular architecture were also applied to different settings of modern contexts such as the case of International School of Bangkok (ISB). Another case which shows the application of specific features that reflect historical connection is the use of the lotus motif of the Sukhothai arch at the Royal Thai Mint Building at Rangsit (Figure 4). The Sukhothai motif symbolizes Sukhothai's past invention of the coin. Other approaches of creating contemporary vernacular characteristics include such features as the symbolization of local utensils (Figure 5), the minimality through breaking down units, and the arrangements of local architectural patterns of the past.

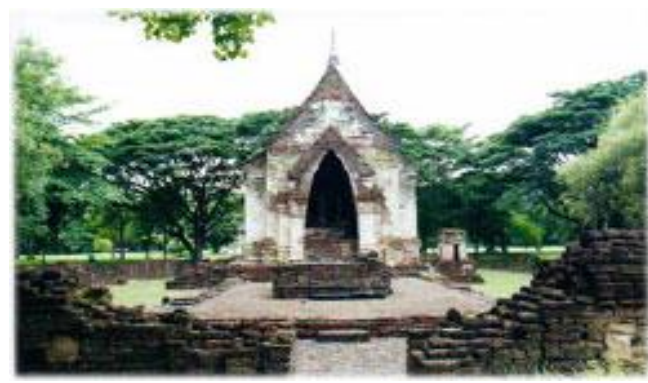

(A)

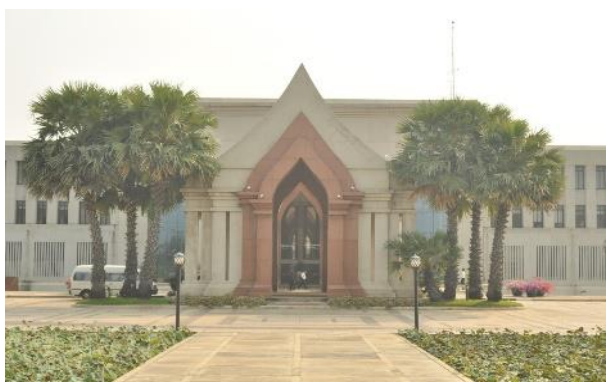

(B)

Figure 4. (A) Wat Suan Kaew in Sukhothai with Original Lotus-shaped Arch; (B) Royal Thai Mint Building's Portico with Sukhothai Nostalgia Source: (A) http://www.sukhothai.go.th/tour/tour_02htm.

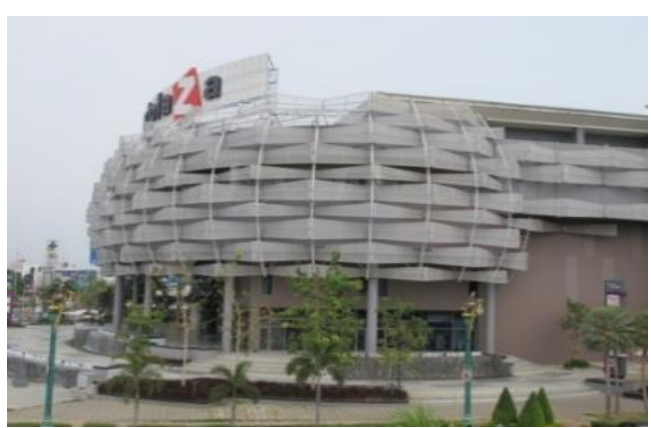

(A)

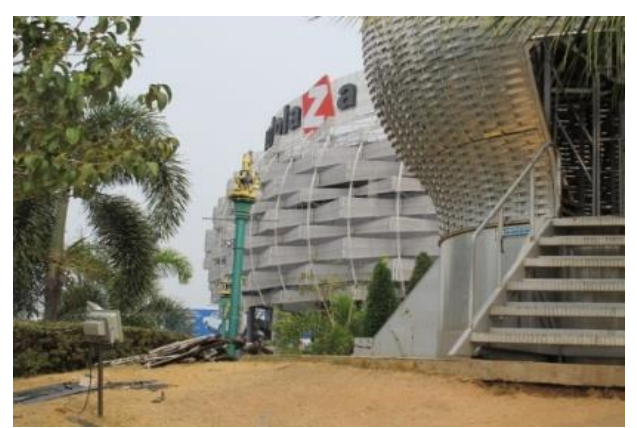

(B)

Figure 5. (A) Central Plaza, Khonkaen's Façade Reflects the Vernacular Form through Symbolizing the Giant 'Kratib' (Woven Rice Container) Opposite (B)

14. See note 8 . 


\section{Aesthetics}

Aesthetics consist of an array of meanings, partly depending on the Thai sense of beauty and the individual's interpretation, according to the value system of a certain timeframe. ${ }^{15}$ Aesthetics contribute to 'delight,' one of the three components (in addition to commodity and firmness) of western architecture as stated in Vitruvius's dictum in Element of Architecture (1624). ${ }^{16}$ Aesthetical dimensions are the bases for the creation of architectural identity. Certain factors contribute to an aesthetic quality in architecture. They are, for instance, project site and building layout, simple functional space arrangement, building composition, form and proportion (Figure 6), material selection, delineation, refinement and coloration.

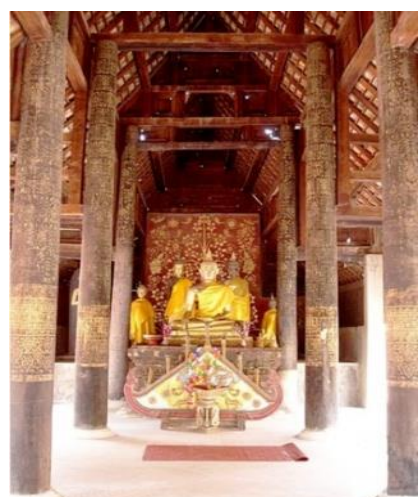

(A)

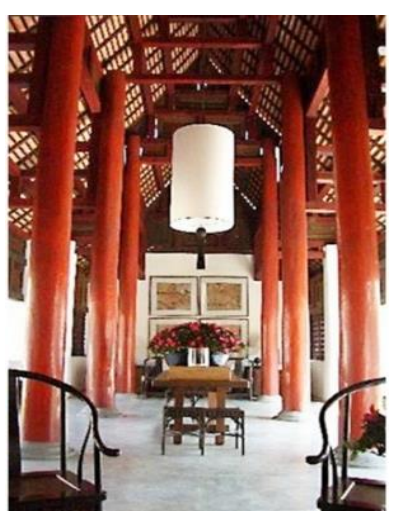

(B)

Figure 6. The Wooden Structure with a Proportion Similar to the 'Golden Section' at (A) Viharn Namtam, Wat Prathat Lumpang Luang, was Applied to (B) Rachamankha Hotel's Lobby by Architect Ongard Satrabhandhu Source: (A) http://bit.ly/2frG2Ph (B) http://bit.ly/2fDVhja.

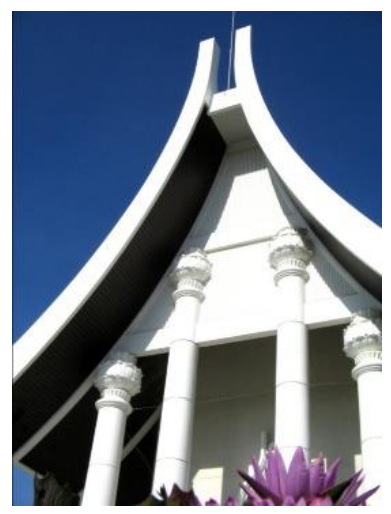

(A)

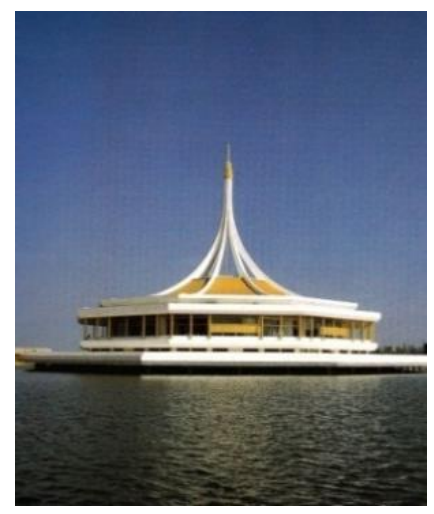

(B)

Figure 7. Graceful Curve in Contemporary Thai Architecture. (A) Ubosot of Wat Phra Dhammakaya and (B) Rachamongkol Hall, Suan Luang Rama IX

15. Chatree Parkitnontakarn, "History of Aesthetics in Traditional Thai House: Built-in Beauty" ASA Journal of the Association of Siamese Architects (2005): 02:48-03:48, 106-108.

16. Kenneth Frampton, "Labour Works \& Architecture," in Meaning in Architecture, ed. Charles Jencks and George Baird (New York: George Braziller), 150-168. 
The following two dominant aesthetic characteristics represent the underlying spirit of creating Thai architectural identity:

Curvilinear delineation: This dominant aesthetic identity focuses on the graceful curve in Thai architecture (Figure 7). The traditional roof structure with catenary curve is one of the architectural features that exhibit gracefulness. Similarly, the Sukhothai arch with its splendid curve represents the graceful lotus symbol (Figure 4).

Refinement: Thai cities are dotted with richly ornamented temples and palaces, each with glittering spired roofs and elegant pediments. In decorative terms, refined quality permeates Thai ornamentation. Refinement reflects the creative spirit and devotion to revered royal and religious architecture. However, in the modern era, the concept of simplification and reduction of refinement, partly due to the lack of talented workmanship, has led to the transformation of aesthetic approach.

\section{Symbolism}

Symbolism focuses on characteristics based predominantly on a belief system and symbolic signification.

Characteristics based on a belief system: Thais, in general, still believe in an orientation of building and furniture arrangement that would enhance fortunate living. Due to the limitation of choice in urban environments, favorable orientation becomes less crucial as a determination factor. Most Thais strongly believe in a future life after death. This Hindu-based belief in reincarnation is a central component of Buddhism in that good actions generate merit, while bad ones generate demerit - a belief in the consequences of one's action. This belief system generates specific architectural patterns based on the cosmological model with Mount Meru, a sacred hub, featuring the reincarnation transformations, which are determined by the accumulation of merit by doing good deeds ${ }^{17}$ (Figure 8).

Characteristics based on symbolic signification: Due to the decline in nationalism and the political need to express collective Thai characteristics for the government office and civic buildings, the concerns of the present-day society to signify modern Thai architectural identity are directed towards the individualistic approach of iconic design. The common iconic features such as high-pitched gable roof, spired roof structure, lotus-shaped motif and sources of water are applied as symbolic elements. Symbolic signification under globalization has become less crucial and less sophisticated. As the social hierarchical order is gradually losing its connection in the modern age, the symbolic messages in terms of size, height, pointed shape, refined decoration, architectural orders that express royal and religious reverence, power and dynamism, have become less distinctive and even confusing. Dhara Dhevi Hotel

17. Sumet Jumsai, Naga: Cultural Origins in Siam and the West Pacific (Oxford: Oxford University Press, 1988), 11-13, 21-28, 45-76; Sumet Jumsai, "Water: Origins of Thai Culture," in Thai Characteristics, ed. M.R. Kukrit Pramoj (Bangkok: Thai Wattana Panich, 1982), 164187. 
in Chiang Mai, where northern religious architectural style dominates the overall hotel complex, has been under severe criticism for its instrumentalization of architecture for commercialism (Figure 9).

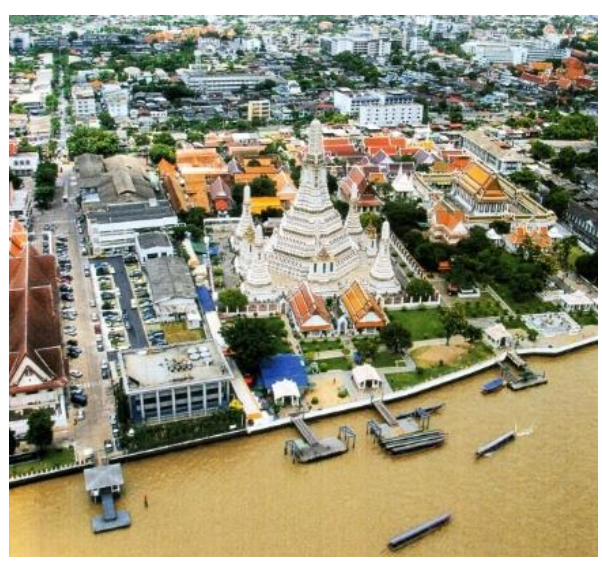

(A)

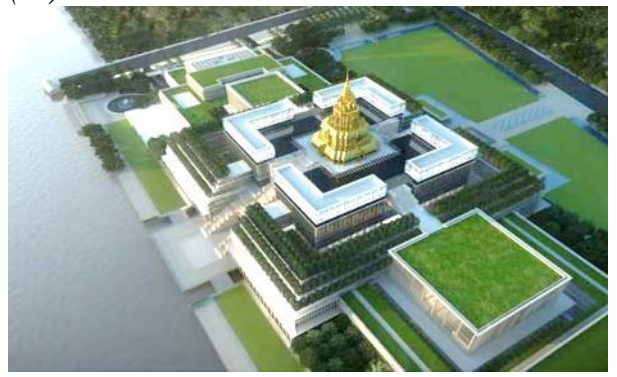

(C)

Figure 8. Architectural Solutions based on Cosmological Model. (A, B) Wat Arun Prang, and $(C, D)$ A Model of the National Assembly Building Topped with Cosmological Structure

Source: (B) Sumet Jumsai, Naga: Cultural Origins in Siam and the West Pacific (Oxford: Oxford University Press, 1988), 123.

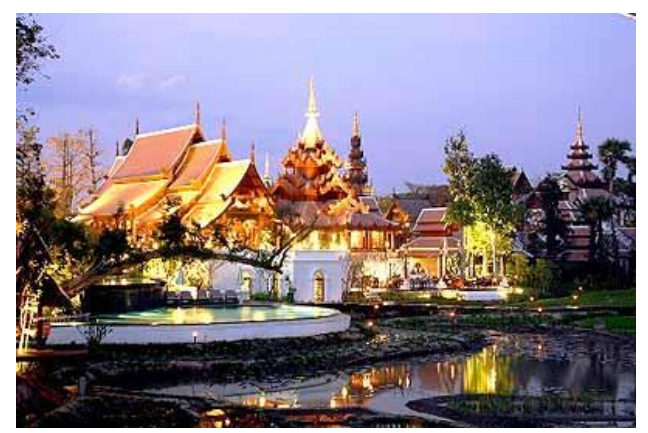

(A)

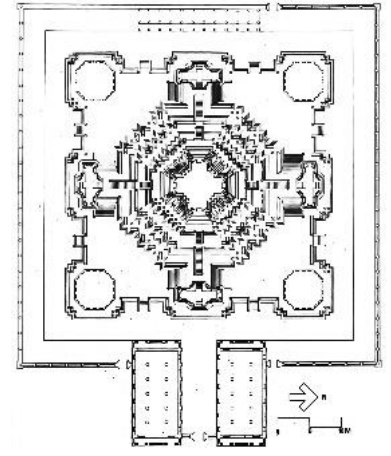

(B)

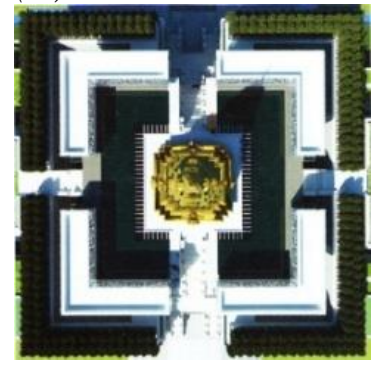

(D)

Figure 9. (A, B) Dhara Dhevi Hotel, Chiang Mai. Source: http://bit.ly/2fDQGhi.

Srisak Wallipodom, a social critic, has expressed his concerns for current individualistic emphasis rather than community-based values: "............ previously we had villages with groups of traditional Thai houses, but now the 
cultural pattern has been replaced with individualism which does not reflect the social need of human beings ....... We are trying to dominate the natural process with present value system., 18

\section{Thainess}

Thai characteristics in terms of Thainess are intrinsic to culture and have transformed over time.

The spirit-driven Thainess is an enduring development through cultural transformation either in formal or in popular Thainess. There were serious attempts to express nationalism through instrumentalization of Thai characteristics in modern functional buildings during periods of political uncertainty both before and after the democratic intervention in 1932. The architectural style known as 'Applied Thai' was severely criticized for its application of Thai roof features on modern structures of office and civic buildings. However, the formal approach to balance tradition with modernity had structurally delimited the freedom in functional planning and finally gave way to modern design in conjunction with encroaching globalization, successive economic development plans and social structure changes.

Nevertheless, popular Thainess prevails in the multiple facets of everyday life in changing Thai society. ${ }^{19}$ It should be noted that the social hierarchical order is still an underlying fundamental hidden in popular culture. Another popular aspect that persistently dictates most of the Thais' behavior in general is the belief in reincarnation under Buddhism which defines the consequences of one's deed.

In examining architecture, both traditional and contemporary, a common determinant persists regarding formal multiplicity and colorful manifestation. Thai architecture from the past to the present reflects the joyful nature of the Thai people. The iconic symbolism reveals inherent playful design - dazzling spires, multi-tiered roofs, conical forms, and multi-colored tile patterns, etc., (Figure 13).

\section{Interviewing Architects and Academics}

The subsequent interviews (in step 3) with the twenty selected architects and academics $^{20}$ focused on design approaches, underlying concepts, sources of inspiration and criticism. The content analyses collectively reveal the essence of the five main categories of fundamental Thai architectural identity in decreasing

18. Srisak Wallipodom, "Traditions in Trends: An Interview on Thai Characteristics in Contem-porary Architecture," ASA Journal of the Association of Siamese Architects (1998): 04:41, 89-90.

19. Philip Cornwel-Smith, Very Thai: Everyday Popular Culture (Bangkok: River Books, 2005).

20. Among the twenty interviewees, half are truly leading professional architects, the rest are academics, of which many are also practicing architects. One is a leading social critic, and one academic in architecture who is also a very keen architectural critic in socio-political issues. 
order of frequency in which each category is mentioned in the interviews. The frequency order reveals the sequence of the non-abstract followed by the more abstract quality (see figures shown in brackets):

Symbolism (39)

Non-Abstract Characteristics (35)

Aesthetics (28)

Abstract Characteristics (27)

Thainess (23)

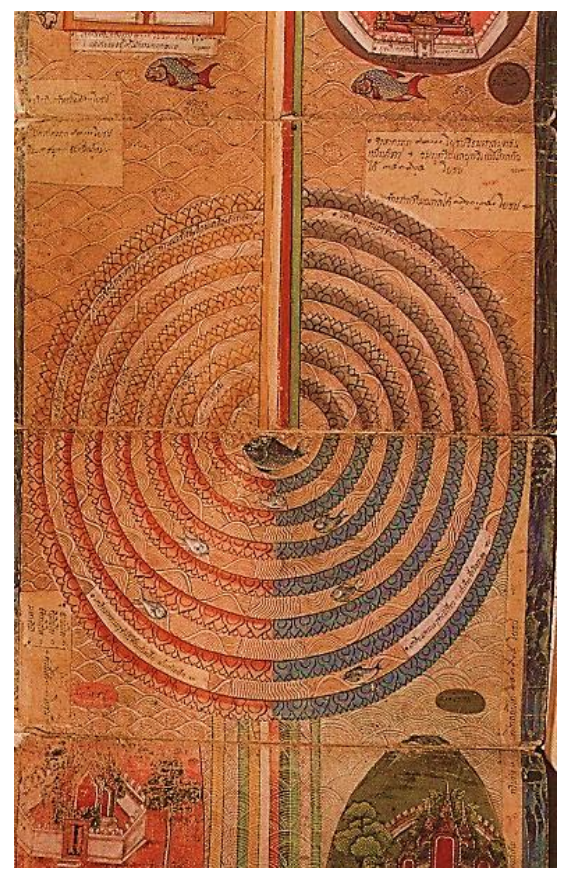

Figure 10. Traiphum Envisioned as Layers of Oceans and Peaks Encircling Mount Meru. (The 1776 Manuscript Version, Royal Edition, No. 10. Thonburi) Source: Sumet Jumsai, Naga: Cultural Origins in Siam and the West Pacific (Oxford: Oxford University Press, 1988), 81.

\section{Symbolism}

The applications of symbolism were most frequently mentioned. Current architects are in favor of symbolic design to signify Thai identity. Architectural characteristics are based on the Thai belief system. Especially the cosmological model (known as 'Traiphum') featuring Mount Meru representing the central vertical peak (Figure 10) connecting The World of Human Being with The World of Hell and The World of Heaven. Many of the interviewees regarded iconic images as a means of communicating specific meaning. These include the social hierarchical order, power, dynamism, sense of community, etc. The design team of the National Assembly Building and architect Chatree Ladalalitsakun in particular have stressed the belief in Buddhism regarding the consequences of one's action - merit or demerit, and more significantly the consciousness of shame in sinful deeds. This is the philosophical argument in proposing a cosmological structure with a golden memorial tower (chedi) on top of the new parliament complex (Figure $8 \mathrm{C}, \mathrm{D}$ ). The design team insists that politicians' behaviors would be ameliorated in a setting designated as "Sapayaspastan," in representing the Assembly Hall as the "House of Merit" with humanizing functions intentionally marked for good deeds.

However, social critic Srisak Wallipodom has expressed serious concerns 
regarding the integration of 'sacred' elements such as the golden spired 'chedi' with the 'profane' National Assembly structure. He stressed that one should be more careful about the underlying symbolic meaning with respect to the context.

Leading architects have proposed iconic images to signify Thai characteristics of contemporary architecture. Among them are Sumet Jumsai, Sinn Phonghanyudh, Nithi Sthapitanonda and Chaiwat Limwatthananon. Architect Sumet has spelt out 4 iconic features representing Thai characteristics: 1) distinctive roof mass; 2) elevated floor for draining; 3) underneath space with raised-on-stilt structure; and 4) the presence of water. Moreover, his Robot Building virtually represents the iconic and playful postmodern design (Figure 11A). Architect Sinn presented Thainess through the application of steep gables and a triangular-shaped icon to tall buildings, such as those at Thaniya Building, the colorful Baiyoke I (Figure 11B) and the Baiyoke 2 (Sky Hotel). However, quite a few interviewees did not mention or even expressed opposition to the application of symbolism. Such architects as Soontorn Boonyatikarn and Amata Luphaiboon are mainly scientific-based and problem-based designers respectively. For the latter, "we are to solve the onsite problems right away and are not concerned with the task of building up an identity." On the other hand, some of the architects/academics of the northeastern region emphasize the application of iconic elements such as the "lietawen" or "pattern with rays of rising sun," originally known as 'liekarntarl,' to be the more general gable or pediment decorative feature. However, for some this approach also displays elements of instrumentalized signification.

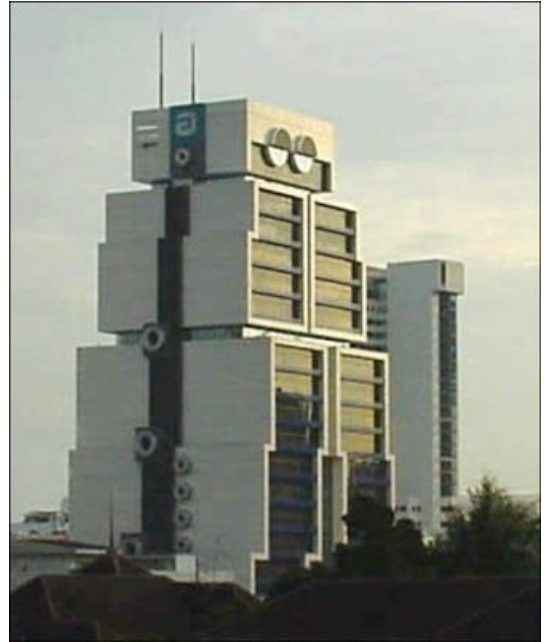

(A)

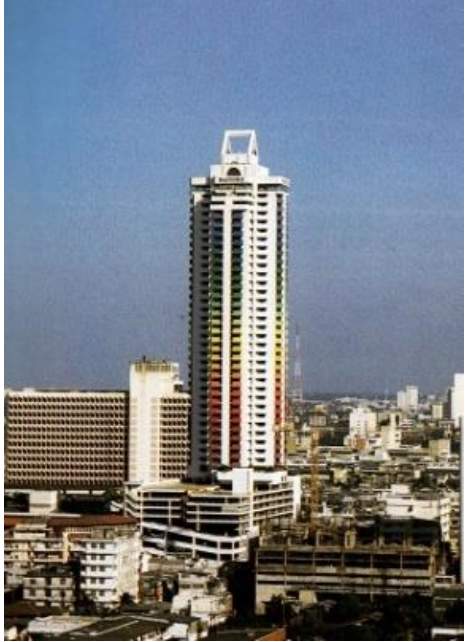

(B)

Figure 11. (A) Playful Iconic Design of the Robot Building and (B) the Colorful Baiyoke I. Both Buildings Reflect the Joyful Nature of Thai People Source: http://www.oknation.net/blog/supawan/2011/10/26/entry-1. 


\section{Non-Abstract Characteristics}

The attributes of non-abstract qualities were mentioned in the second order of frequency by the interviewees. While a few architects did directly mention the importance of design in harmony with nature, (including landscape layout), and integrating natural settings with built environment, they also focused on the design of semi-outdoor space or 'grey-area', which is particularly dominant in the works of architects Chatree Ladalalitsakun and Theeraphon Niyom. Many architects are in favor of contemporary vernacular architecture, the unique characteristics of which are the outcome of material input, formal organization and the applications of components and elements. Architect/academic Pirast Pacharaswate has illustrated the vernacular concept of his East House which demonstrates innovative modern Thai architecture (Figure 12A). A comparatively more conventional approach is the Local Hero House designed by architect/academic Khiensak Seangklieng which nostalgically reflects Sumet Chumsai's four iconic features representing Thai characteristics (Figure 12B).

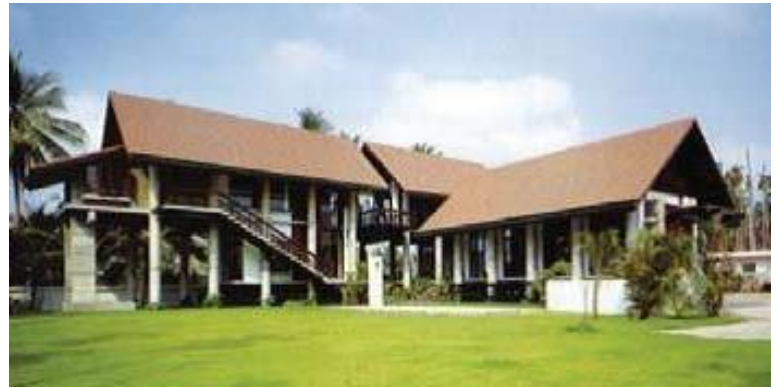

(A)

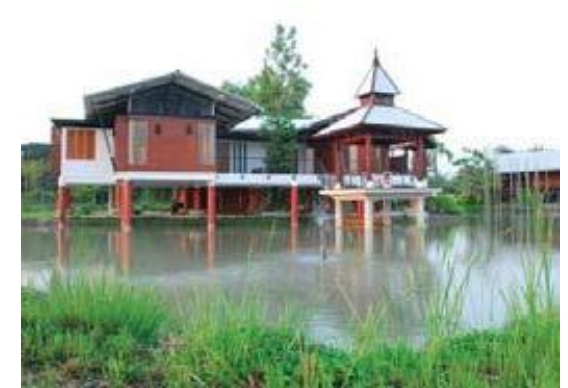

(B)

Figure 12. Vernacular Concept of Modern Thai Architecture: (A) East House and $(B)$ Local Hero House

\section{Aesthetics}

The interviews revealed attributes that architects use to contribute to the multiple aesthetic dimensions. The most favorable factors are the formal aspects such as composition, form and proportion. Secondary factors are the concerns of site condition, material selection, and coloration - in particular the application of gold which is associated with good fortune.

As for aesthetic qualities, a few interviewees insisted that refinement in decorative works was the fundamental of aesthetics in architecture. Surprisingly, no one mentioned the curvilinear style which contributes to the generally accepted graceful appearance of Thai architecture.

It should be noted that a few architects were concerned with functional planning through simple organization in attaining fundamental aesthetic quality. The designs of the architects Ongard Satrabhandhu and Amata Luphaiboon did, however, reflect this aesthetic quality. This precept of simplicity is in fact the underlying pared down aesthetics of modernism. 


\section{Abstract Characteristics}

The architects in general are less concerned with intrinsic abstract characteristics. Transparency / spaciousness and shadiness / coolness, gained through the natural sources of foliage, water and wind, were intangible attributes mentioned by many interviewees. Fewer were concerned with lightness/ buoyancy and the sequence of darkness, dimness and brightness. The latter is the concern of visual comfort as a design outcome conceived by interviewees Soontorn Boonyatikarn and Chatree Ladalalitsakun. Khiensak Seangklieng, an architect/academic, is the only interviewee who pointed out serenity as inherent Thai architectural identity. As a whole, the concerns for comfortable living conditions gained through scientific research as insisted by Soontorn Boonyatikarn, reflect the achievements of Thai wisdom in dealing with severe climatic and environmental conditions. He stressed in his interview that the Thai architectural identity can be created through providing: 1) thermal comfort, 2) lighting comfort, 3) acoustical comfort and 4) visual comfort. However, the approach is beyond the formal tradition of Thai architecture.

\section{Thainess}

The architects realize that spirit-driven Thainess is an enduring inheritance of culture. However, they hold rather different attitudes toward such development. Despite the democratic ruling, many Thais still feel obliged to the social hierarchical order and the patronage system. As pointed out by M.R. Kukrit Pramoj, the need to reinstall interpersonal behavior with respect to the recognition of social hierarchical status (knowing 'teetum teesoong'). And because of the influence of Buddhism on the merit system, national unity can be attained through adherence to royal centrality of spirit. ${ }^{21}$ It should be noted that, according to academic Chartree Prakit-nontakarn, Thai style in the history of modern architecture was developed in association with building up nationalism.

Regarding the cultural transformation, no specific issue was directly related to either formal or popular Thainess. However, interviewees such as architects Sumet Jumsai and Sinn Phonghanyudh mentioned the joyful nature of the Thai people. Their works on iconic symbolism as well as the application of large field of color display playful designs (Figure 11) which are consistent with the traditional architecture of multiplicity (Figure 13).

21. Saichol Satayanurak, The Main Stream of Building up "Thainess" and the "Reality" that "Thainess" Creates (in Thai), retrieved on March 7, 2014 from http://www.fringer.org/ wp-content/writings/thainess.pdf, 1-28. 


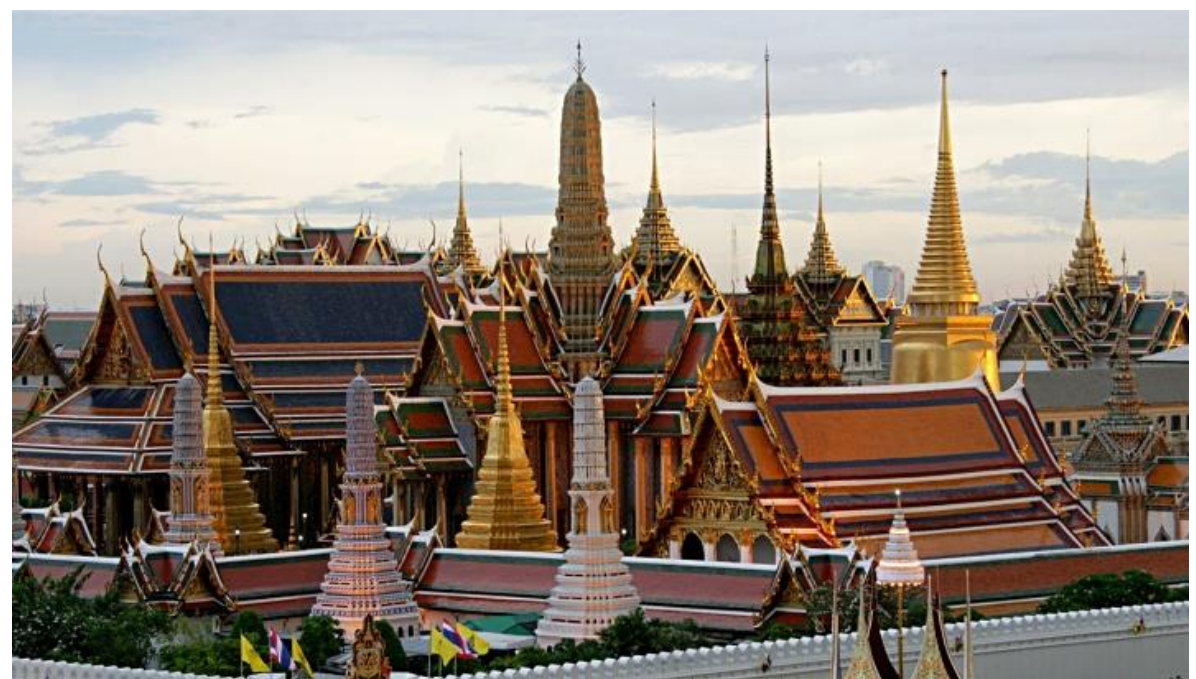

Figure 13. Architectural Multiplicity Inside the Compound of The Temple of Emerald Buddha

Source: https://i.ytimg.com/vi/IBwRgNl6K8Y/maxresdefault.jpg.

\section{Conclusions and Recommendation}

In this research, five main categories of fundamentals of Thai architecture from the past to present have been unveiled through integrated research approaches in generating output from reviews, surveys and interviews. The following conclusions can be reached for the five main categories:

1. Abstract characteristics include lightness/buoyancy, transparency/ spaciousness, enclosure, shadiness/coolness, brightness/dimness/darkness, and tranquility/quietness. These abstract qualities reflect the Thai spirit nurtured through conditions of tropical climate and Thai wisdom.

2. Non-abstract characteristics are mainly the outcomes of localism for both traditional and contemporary architecture. The effects can be achieved by means of design in harmony with nature, being an integral part of a natural setting, gaining more green areas in landscape layout and in enclosed space, possibly with a vertical garden. They are instrumental in creating environmental sustainability and conserving energy. This is similar to the concept of LEED, the world class certification, and TREES for Thailand. The Thai wisdom utilized in creating comfortable living conditions as codified in the traditional Thai house is inherent in the contemporary vernacular design regarding climatic protection, the provision of semi-outdoor space and the enclosed courtyard.

3. There are certain structural limitations for the application of the curvilinear style such as the graceful catenary curve of traditional roof structure. Similarly, the refined decorative features, originally revered in both royal and religious architecture, are becoming less sophisticated in the modern context, in which talented workmanship is lacking.

4. Symbolism through the application of iconic image is logically apparent in both traditional and contemporary architecture, especially images that are 
related to the prevalent belief system of Buddhism. The widespread belief in reincarnation among the Thai people has permeated daily life. In architecture, the symbolic representation is based on the cosmological model ('Traiphum') which accommodates the Three Worlds for a human being after death.

The concerns to express modern Thai architectural identity are directed towards iconic design. The favorable applications of iconic features are highpitched gable roof, spired roof structure, lotus-shaped motif and the pool as a source of water.

5. Thainess reflects the Thai spirit and nature of the Thais nurtured through cultivation. Spirit-driven Thainess, found in both formal and popular development, reflects the enduring history of a changing Thai society. The formal multiplicity and colorful manifestation of Thai architecture, past and present, are partly the outcomes of the joyful nature of the Thai people.

Throughout the history of Thai architecture, a remarkable capacity for the accumulation of external influences and architectural adaptation over time should be noted. Thus, some succinct recommendations can be proposed:

1. Additional research should focus on the symbolic reinvention rather than the iconic applications of conventional images and elements.

2. In addition to certain existing architectural solutions, greater efforts should be made to enhance social cohesion and quality of life.

3. The Thai identity of contemporary architecture should also be considered in terms of relevance to the global context. The architectural solutions must be responsive to global issues such as global warming and climate changes, as well as to the technology-driven challenges.

\section{Acknowledgements}

My sincere thanks to The Thailand Research Fund (TRF) in supporting the research series project: The Creation of Modern Thai Architectural Identity.

\section{Bibliography}

Chaichongrak, Ruethai, Somchai Nil-athi, Ornsiri Panin and Saowalak Posayanonda. The Thai House: History and Evolution. Bangkok: River Books, 2002, 19-97.

Cornwel-Smith, Philip. Very Thai: Everyday Popular Culture. Bangkok: River Books, 2005.

Frampton, Kenneth. "Labour Works \& Architecture." In Meaning in Architecture. Edited by Charles Jencks and George Baird. New York: George Braziller, 1969: 150-168.

Horayangkura, Vimolsiddhi. "The Architecture of Thailand: Change amid Continuity." In Transforming Traditions: Architecture in the ASEAN Countries. Edited by Jon Lim. ASEAN Studies Publication Series, The ASEAN Committee on Culture and Information (COCI). Singapore: Unique Press, 2001: 240-245.

Horayangkura, Vimolsiddhi. "The Creation of Cultural Heritage: Towards Creating a Modern Thai Architectural Identity." Manusya Journal of Humanities 13, No. 1 (2010): 60-80.

Horayangkura, Vimolsiddhi, Bootsakorn Sethaworakij and Vira Inpuntung, Funda- 
mentals of Thai Architectural Identity [in Thai]. A research report of the research series project: The Creation of Modern Thai Architectural Identity. Funded by The Thailand Research Fund. Pathumthani: Faculty of Architecture and Planning, Thammasat University, 2015.

Hinchiranan, Nij. "Thai Architecture: Indigenous Architecture for People of the Central Region." ASA Journal of the Association of Siamese Architects (1996): 110117.

Jumsai, Sumet. "Water: Origins of Thai Culture." In Thai Characteristics [in Thai]. Edited by M.R. Kukrit Pramoj. Bangkok: Thai Wattana Panich, 1982: 164-187.

Jumsai, Sumet. Naga: Cultural Origins in Siam and the West Pacific. Oxford: Oxford University Press, 1988: 11-13, 21-28, 45-76.

Kalyanamitra, Joti. Traditional Thai Architecture. In M.R. Kukrit Pramoj (Editor), Thai Characteristics (in Thai). Bangkok: Thai Wattana Panich, 1982: 310-364.

Lim, William Siew Wei and Tan Hock Beng. The New Asian Architecture. Singapore: Select Books, 1998.

Pimviriyakul, Vannapa. Light in Thai Places: A Cultural Intepretation of Thai Buddhist Architecture. College Station: Texas A\&M University, 2001, 181.

Povatong, Pirasri. Building Siwilai: Transformation of Architecture and Architectural Practice in Siam during the Reign of Rama V, 1868-1910. Doctoral dissertation. University of Michigan, 2011: 5-10.

Prakitnontakarn, Chatree. "History of Aesthetics in Traditional Thai House: Built-in Beauty" (Part 1). ASA Journal of the Association of Siamese Architects (2005): 02:48-03:48, 106-108.

Rapoport, Amos. House Form and Culture. Englewood Cliffs, N.J.: Prentice-Hall, 1969, 46-82.

Satayanurak, Saichol. "The Main Stream of Building up "Thainess" and the "Reality" that "Thainess" Creates [in Thai]. Retrieved on March 7, 2014 from http:// www.fringer.org/wp-content/writings/thainess.pdf, 1-28.

Thaveeprungsriporn, Piyalada M.L. "Ruan Thai: An Aesthetic of Femininity?" In Architecture Wisdom [in Thai]. Edited by Ornsiri Panin, M.L. Piyalada Thaveeprungsriporn and Thirdsak Techakijkajorn. Bangkok: Archi-press, 2003: 68-96.

Tuan, Yi-Fu, Space and Place: The Perspective of Experience. Minneapolis: University of Minnesota Press, 1981, 101-117.

Wallipodom, Srisak. "Traditions in Trends: An Interview on Thai Characteristics in Contemporary Architecture." ASA Journal of the Association of Siamese Architects (1998) (04:41): 89-90. 
